\title{
Lack of influence of test meal fatty acid composition on the contribution of intestinally-derived lipoproteins to postprandial lipaemia
}

\author{
Kim G. Jackson*†, Antonios Zampelas, Jacky M. E. Knapper, Caroline C. Culverwell, John Wright, \\ Barry J. Gould and Christine M. Williams $\dagger$ \\ Centre for Nutrition and Food Safety, School of Biological Sciences, University of Surrey, Guildford GU2 5XH, UK
}

(Received 11 February 1998 - Revised 5 June 1998 - Accepted 22 June 1998)

\begin{abstract}
The extent and duration of postprandial lipaemia have been linked to risk of CHD but the influence of dietary variables on, and the relative contributions of, exogenous (chylomicron) and endogenous (VLDL) triacylglycerols to the total lipaemic response have not been comprehensively evaluated. In the present study the triacylglycerol, apolipoprotein (apo) B-48 and retinyl ester (RE) responses to three test meals of varying monounsaturated (MUFA) and saturated fatty acid (SFA) content were measured in the triacylglycerol-rich lipoprotein (TRL) fraction of plasma $(\rho=1.006 \mathrm{~g} / \mathrm{ml})$ for $9 \mathrm{~h}$ after meal consumption. Fifteen healthy normolipidaemic young men consumed, on separate occasions, three test meals which were identical apart from their MUFA and SFA contents. Expressed as a percentage of total energy the MUFA/SFA contents of the meals were: (1) $12 \% / 17 \%$; (2) $17 \% / 12 \%$ and (3) $24 \% / 5 \%$. The contribution of the intestinally-derived lipoproteins (chylomicrons) to the lipaemic response was investigated by determining the time to reach peak concentration and the total and incremental areas under the time response curves (AUC and incremental AUC) for RE, apoB-48 and triacylglycerol in the TRL fraction. No significant differences in these measurements were observed for the three meals. However, visual comparison of the postprandial responses to the three meals suggested that as meal MUFA content increased there was a tendency for the triacylglycerol, apoB-48 and $\mathrm{RE}$ responses to become biphasic as opposed to the typical monophasic response seen with the $12 \%$ MUFA $17 \%$ SFA meal. Comparison of the apoB-48 and RE responses for the three test meals confirmed other workers' findings of delayed entry of RE relative to apoB-48 in TRL. The value of the two markers in investigating dietary fat absorption and metabolism is discussed.
\end{abstract}

Fatty acids: Retinyl ester: Apolipoprotein B-48

Raised levels of chylomicrons (CM) and CM remnants, which circulate following consumption of a meal, have been implicated in the aetiology of atherosclerosis (Mahley, 1982; Stender \& Zilversmit, 1982; Brown \& Goldstein, 1983). Dietary postprandial studies have highlighted the importance of the measurement of these intestinally-derived triacyglycerol-rich lipoproteins (TRL) (Weintraub et al. 1988; Demacker et al. 1991). Recent evidence suggests that the fatty acid composition of the test meal may influence the absorption, synthesis and secretion of dietary triacylglycerol, as well as the size of the CM particle. In this way meal fat type may modify the postprandial lipaemic response directly, rather than indirectly through alterations in hepatic VLDL output, and this emphasizes the need to be able to distinguish the contributions to lipaemia of the two types of TRL particles. Unsaturated fatty acids, especially polyunsaturated fatty acids (PUFA), have been shown to produce an attenuated lipaemic response and to increase the size of the CM particles compared with those from a test meal containing saturated fatty acids (SFA) (Weintraub et al. 1988; Demacker et al. 1991; Levy et al. 1991; Zampelas et al. 1994; Sakr et al. 1997). However, very little is known about the effect of $n-9$ monounsaturated fatty acids (MUFA), especially oleic acid, on the extent of lipaemia or on the composition or size of the CM particles during postprandial lipaemia (Brouwer et al. 1993; de Bruin et al. 1993).

Currently there are two methods available for the measurement of intestinally-derived lipoproteins, namely indirect labelling of $\mathrm{CM}$ with an ester of vitamin $\mathrm{A}$ by

\footnotetext{
Abbreviations: apo, apolipoprotein; AUC, area under the curve; CM, chylomicrons; MUFA, monounsaturated fatty acids; PUFA, polyunsaturated fatty acids; RE, retinyl esters; SFA, saturated fatty acids; TRL, triacylglycerol-rich lipoproteins.

* Corresponding author: Dr Kim G. Jackson, fax + 44 (0)118931 0080, email k.jackson@afnovell.reading.ac.uk

$\uparrow$ Present address: Hugh Sinclair Unit of Human Nutrition, Department of Food Science and Technology, University of Reading, Whiteknights, Reading RG6 6AP, UK.
} 
K. G. Jackson et al.

incorporation of retinyl palmitate into the test meal (Hazzard \& Bierman, 1976) and the direct measurement of apolipoprotein (apo) B-48, the specific transport protein of CM. The vitamin A loading method is a popular method which has been used in a number of studies to date in animals (Ross \& Zilversmit, 1977; Kita et al. 1982) and human volunteers (Berr \& Kern, 1984; Cortner et al. 1987; Weintraub et al. 1987; Krasinski et al. 1990a,b; Ruotolo et al. 1992). However, Krasinski et al. (1990a) have highlighted limitations of the use of retinyl esters (RE) as markers for CM. These include a delay in the postprandial RE response in comparison with triacylglycerol and apoB-48 responses in the plasma and TRL fractions, but more importantly, evidence of transfer of the RE label onto other lipoprotein fractions (LDL and HDL), 9-12 h following the test meal, making it less valuable as a specific marker of CM. ApoB-48 is exclusively associated with the CM particle and since it is not exchanged with other lipoproteins during postprandial lipaemia, provides a specific direct measurement of the number of CM particles in the circulation (Karpe \& Hamsten, 1995). The aims of this present study were to compare the postprandial lipaemic responses of normal subjects following meals of varying MUFA and SFA content and to compare the use of the vitamin A loading technique and apoB-48 as markers of CM-specific lipaemia in test-meal studies.

\section{Materials and methods}

\section{Subjects}

Fifteen healthy, young, normolipidaemic male volunteers, with a mean age of $22 \cdot 3$ (SD 3.2) years, BMI of $23.0($ SD 2.0) $\mathrm{kg} / \mathrm{m}^{2}$ and a total habitual fat intake of $37 \%$ energy, of which $14 \%$ was derived from SFA, $11 \%$ from MUFA and $6 \%$ from PUFA, were recruited. The volunteers all satisfied the following inclusion criteria: they were all between 18 and 30 years old, with a BMI between 19 and $26 \mathrm{~kg} / \mathrm{m}^{2}$ and an habitual diet representative of the UK population (35$45 \%$ energy as fat, comprising approximately $17 \%$ SFA, $12 \%$ MUFA and 5\% PUFA). They did not have any previous history of hyperlipidaemia, diabetes or other endocrine or liver diseases. Their level of aerobic exercise was less than three sessions of $30 \mathrm{~min} /$ week and their intake of alcohol was less than 30 units/week. They were not trying to lose weight or taking dietary fatty acid supplements. The volunteers were recruited following screening for blood lipid, glucose and haemoglobin levels which were all within normal limits (triacylglycerol, mean $1 \cdot 1$ (SD $0 \cdot 3$ ) mmol/l; cholesterol, mean 4.3 (SD 0.9) mmol/l; glucose, mean 4.8 (SD 0.4) mmol/l; haemoglobin, mean 15.7 (SD 9.9) $\mathrm{g} / \mathrm{l})$, and all had normal liver enzyme values.

The study was approved by the ethics committee of the University of Surrey and the Royal Surrey County Hospital and all volunteers gave informed consent at the beginning of the study.

\section{Study day procedure}

Test-meal composition. Volunteers were randomly allocated to consume the three acute test meals of varying
Table 1. Fatty acid composition* $(\mathrm{g} / 40 \mathrm{~g})$ of test meals containing 12 , 17 and $24 \%$ dietary energy as monounsaturated fatty acids (MUFA)

\begin{tabular}{|c|c|c|c|}
\hline \multirow[b]{2}{*}{ Fatty acid } & \multicolumn{3}{|c|}{ MUFA meal (\% energy) } \\
\hline & 12 & 17 & 24 \\
\hline $8: 0$ & 1.1 & 0.6 & - \\
\hline $10: 0$ & 1.1 & 0.5 & - \\
\hline 12:0 & 7.2 & 3.6 & - \\
\hline $14: 0$ & 2.5 & 1.3 & - \\
\hline $16: 0$ & 6.1 & 6.5 & 4.6 \\
\hline 18:0 & 1.2 & $1 \cdot 1$ & 0.9 \\
\hline 20:0 & 0.2 & 0.2 & 0.2 \\
\hline 22:0 & trace & trace & - \\
\hline 24:0 & trace & trace & - \\
\hline $16: 1$ & 0.2 & 0.3 & 0.4 \\
\hline 18:1 & $13 \cdot 8$ & $19 \cdot 6$ & 27.5 \\
\hline 18:2 & 4.2 & $4 \cdot 1$ & 4.2 \\
\hline $18: 3$ & 0.1 & 0.2 & 0.3 \\
\hline
\end{tabular}

* Determined from computerized food database (FOODBASE, The Institute of Brain Chemistry and Human Nutrition, London, UK).

MUFA and SFA content which were presented in the form of a milk shake containing $40 \mathrm{~g}$ of the test oil, white bread sandwiches with strawberry jam, and water. The test oils were mixtures of coconut oil, palm oil, olive oil and sunflower oil to provide the fatty acid profiles for the three test meals which were: (1) $12 \%$ MUFA meal $(17.2 \%$ dietary energy as SFA, $12.0 \%$ MUFA and 5.0\% PUFA), (2) $17 \%$ MUFA meal (12.3\% SFA, $17 \cdot 1 \%$ MUFA and $4.6 \%$ PUFA) and (3) $24 \%$ MUFA meal (5.4\% SFA, $24.1 \%$ MUFA and $4.6 \%$ PUFA). Table 1 shows the full fatty acid compositions of the three test meals. The test meal supplied $4.18 \mathrm{MJ}$ energy, in the form of $150 \mathrm{~g}$ carbohydrate, $24 \mathrm{~g}$ protein and $42 \mathrm{~g}$ fat. Retinyl palmitate (oil form, $100 \mathrm{mg}$; Roche, Welwyn Garden City, Herts., UK) was added to the milk shake.

Postprandial study day. On the day before the postprandial study day, volunteers were asked to avoid alcohol and strenuous exercise, and to refrain from eating after 20.00 hours. Volunteers arrived at the Royal Surrey County Hospital Investigation Unit following a $12 \mathrm{~h}$ overnight fast on three separate occasions separated by more than 1 week. An indwelling cannula was inserted into the antecubital vein of the forearm and two fasting blood samples were taken before giving the test meal, which was consumed within $20 \mathrm{~min}$. Every $2 \mathrm{~h}, 200 \mathrm{ml}$ decaffeinated, sugar-free drink was consumed and no food was allowed during the $9 \mathrm{~h}$ test period. Blood samples were collected every $30 \mathrm{~min}$ for the first $2 \mathrm{~h}$ of the study and then hourly until $9 \mathrm{~h}$ following the test meal. The test meals were all well tolerated by the volunteers with no unpleasant side-effects.

\section{Plasma separation and analytical methods}

Preparation of the triacylglycerol-rich lipoprotein fractions. Blood samples were collected into heparinized tubes (L.I.P., Shipley, W. Yorks., UK) and spun at $1700 \mathrm{~g}$. Plasma was stored in sterile glass bottles containing no anticoagulant at $4^{\circ}$ overnight until the TRL fraction 
$(\rho<1.006 \mathrm{~g} / \mathrm{ml})$ was prepared by following the procedure of Grundy \& Mok (1976). Plasma $(3.5 \mathrm{ml})$ was overlayered with $3.5 \mathrm{ml}$ saline $(9 \mathrm{~g} \mathrm{NaCl} / 1, \rho=1.006 \mathrm{~g} / \mathrm{ml})$ and ultracentrifuged in $38 \mathrm{ml}$ polycarbonate tubes (Beckman Instruments (UK) Ltd, High Wycombe, Bucks., UK) at $4.83 \times 10^{6} \boldsymbol{g}_{\max }$ in a 50.2 Ti rotor (Beckman). TRL (creamy layer floating on the surface; $1.2 \mathrm{ml}$ ) was carefully isolated, divided into portions and stored at $-20^{\circ}$ for future analyses. To protect apoB-48 from proteolytic cleavage, a preservative cocktail was added at a concentration of $50 \mathrm{ml} / \mathrm{l}$ of the apoB-48-containing sample (Edelstein \& Scanu, 1986). Samples for the analysis of RE were covered in aluminium foil to protect them from degradation by the light.

Measurement of TRL triacylglycerols. Triacylglycerols in the TRL fraction were measured on the Cobas-Mira Analyser (Roche Products Ltd, Welwyn Garden City, Herts., UK) using enzyme-based colorimetric kits supplied by Roche Diagnostics Ltd (Welwyn Garden City, Herts., UK).

Measurement of TRL apoB-48 and retinyl esters. TRL apoB-48 was measured using a specific competitive ELISA, the intra-assay $\mathrm{CV}$ was $3.8 \%$ and the inter-assay $\mathrm{CV}$ was $7.2 \%$ at $4.2 \mu \mathrm{g} / \mathrm{ml}$ (Lovegrove et al. 1996). Normal-phase HPLC was used to measure total RE in the TRL fraction (Ruotolo et al. 1992). The inter-assay CV was $1.9 \%$ and inter-assay $\mathrm{CV}$ was $3.2 \%$ at $5 \mu \mathrm{g} / \mathrm{ml}$.

\section{Statistical analysis}

Results presented in the postprandial time response curves are mean values (standard error bars have been removed to improve clarity of presentation for observing the patterns of the triacylglycerol, apoB-48 and RE responses since no statistical differences were observed). Total and incremental areas under the curve (AUC and incremental AUC respectively) were calculated using the trapezoidal rule (Matthews et al. 1990). In tables, results are presented as mean values and standard deviations (SD). ANOVA was applied to the responses of the subjects to the three acute test meals using the statistical package Instat (Macintosh version 2, San Diego, CA, USA). Statistical differences were then allocated using the Student-Newman-Keuls multiple comparisons post test. Repeated measures ANOVA was performed using Datadesk 4.1 (Data Description Inc., Ithaca, NY, USA). Data were checked for normality and transformed where necessary before the statistical analysis was performed. Values of $P<0.05$ were taken as significant.

\section{Results}

\section{Fasting TRL concentrations}

The fasting concentrations for triacylglycerol and apoB-48 were not significantly different among study days for each of the test meals: triacylglycerol (mmol/l), 12\% MUFA meal 0.45 (SD 0.20), $17 \%$ MUFA meal 0.46 (SD 0.23) and $24 \%$ MUFA meal 0.45 (SD 0.18); apoB-48 ( $\mu \mathrm{g} / \mathrm{ml}), 12 \%$ MUFA meal 0.45 (SD 0.27), $17 \%$ MUFA meal 0.54 (SD 0.29 ) and $24 \%$ MUFA meal 0.39 (SD 0.24). Fasting RE concentrations were below the limit of detection of the HPLC system.

\section{Postprandial TRL responses}

TRL responses did not differ for the three meals, as illustrated by lack of significant differences in the individual times to reach peak concentration, AUC and incremental AUC for the triacylglycerol, apoB-48 and RE responses for the three acute test meals (Table 2). There was a consistent trend for the RE response to peak later than those for triacylglycerol and apoB-48 following each of the test meals (Table 2).

Comparison of the postprandial TRL patterns for the three MUFA test meals. To enable the postprandial

Table 2. Total and incremental areas under the time response curve (AUC and IAUC) and individual times to reach peak concentration of the triacylglycerol, apolipoprotein B-48 and retinyl ester responses in the plasma triacylglycerol-rich lipoprotein fraction of fifteen male volunteers following three acute test meals containing 12 , 17 or $24 \%$ dietary energy as monounsaturated fatty acids (MUFA)*

(Mean values and standard deviations)

\begin{tabular}{|c|c|c|c|c|c|c|}
\hline & \multicolumn{6}{|c|}{ MUFA meal (\% energy) } \\
\hline & \multicolumn{2}{|c|}{12} & \multicolumn{2}{|c|}{17} & \multicolumn{2}{|c|}{24} \\
\hline & Mean & SD & Mean & SD & Mean & SD \\
\hline \multicolumn{7}{|l|}{ Triacylglycerol } \\
\hline AUC (mmol/l.min) & 373.8 & $132 \cdot 9$ & 363.9 & $143 \cdot 8$ & $402 \cdot 0$ & $198 \cdot 3$ \\
\hline IAUC (mmol/l.min) & $142 \cdot 4$ & 75.7 & 122.4 & 61.9 & 168.3 & $150 \cdot 0$ \\
\hline Time to peak (min) & $272 \cdot 0$ & 117.5 & 234.0 & $119 \cdot 0$ & 268.2 & 130.5 \\
\hline \multicolumn{7}{|l|}{ Apolipoprotein B-48 } \\
\hline AUC $(\mu \mathrm{g} / \mathrm{ml} . \mathrm{min})$ & $507 \cdot 4$ & $261 \cdot 7$ & $595 \cdot 1$ & $290 \cdot 7$ & 510.9 & $323 \cdot 2$ \\
\hline IAUC ( $\mu \mathrm{g} / \mathrm{ml} . \mathrm{min})$ & 265.2 & $177 \cdot 8$ & 303.5 & $258 \cdot 5$ & $299 \cdot 1$ & $240 \cdot 3$ \\
\hline Time to peak (min) & 261.4 & 90.0 & 263.6 & 105.4 & 291.4 & $126 \cdot 4$ \\
\hline \multicolumn{7}{|l|}{ Retinyl ester } \\
\hline AUC $(\mu \mathrm{g} / \mathrm{ml} . \mathrm{min})$ & $352 \cdot 1$ & 159.8 & $404 \cdot 0$ & $132 \cdot 0$ & 469.8 & $249 \cdot 1$ \\
\hline IAUC ( $\mu \mathrm{g} / \mathrm{ml} . \mathrm{min})$ & $352 \cdot 1$ & $159 \cdot 8$ & $404 \cdot 0$ & $132 \cdot 0$ & 469.8 & $249 \cdot 1$ \\
\hline Time to peak (min) & $346 \cdot 2$ & 98.5 & $346 \cdot 2$ & 95.2 & $327 \cdot 7$ & $105 \cdot 6$ \\
\hline
\end{tabular}

* For details of meals and procedures, see Table 1 and pp. 52-53. Statistical analysis revealed no significant differences. 

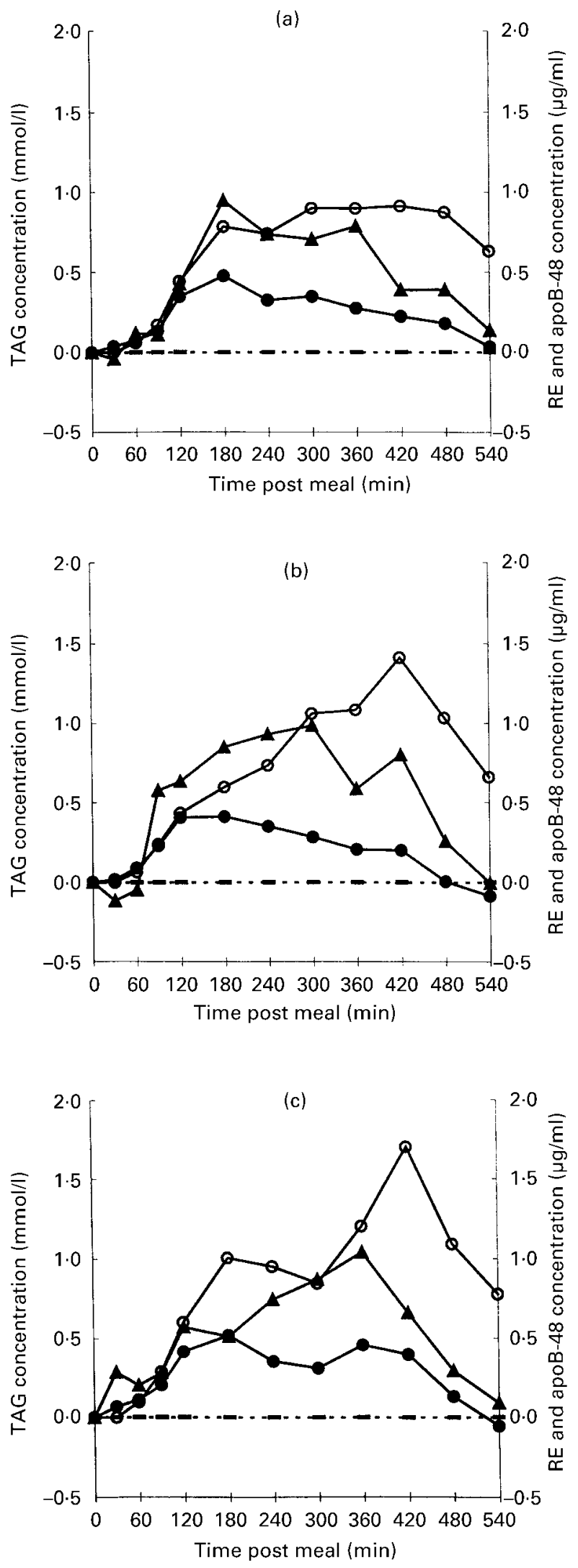

patterns of response to be compared for the three test meals, the triacylglycerol and apoB-48 responses were corrected for their fasting concentration to allow visual comparison with the RE response. The graphs are presented to the same scale to enable the magnitude of the responses to be compared (Fig. 1).

$12 \%$ MUFA acute test meal. Following consumption of the meal, each of the three variables showed a marked increase in their postprandial concentrations, showing peak responses at $180 \mathrm{~min}$. Both triacylglycerol and apoB48 then returned to baseline levels with apoB-48 demonstrating a slight shoulder peak at $360 \mathrm{~min}$. The RE response plateaued between 240 and $480 \mathrm{~min}$ and remained elevated above baseline levels at the end of the $9 \mathrm{~h}$ test period (Fig. 1(a)).

$17 \%$ MUFA acute test meal. The triacylglycerol response demonstrated a peak between 120 and $180 \mathrm{~min}$ before returning to fasting concentrations at the end of the $9 \mathrm{~h}$ study period. Both apoB-48 and RE responses reached peak values later, with apoB-48 at $300 \mathrm{~min}$ and $\mathrm{RE}$ at $420 \mathrm{~min}$. Unlike the triacylglycerol and apoB-48 responses, $\mathrm{RE}$ concentrations did not return to fasting concentrations at $9 \mathrm{~h}$ (Fig. 1(b)).

$24 \%$ MUFA acute test meal. The triacylglycerol, RE and apoB-48 responses all demonstrated biphasic patterns to this test meal. RE and triacylglycerol showed an initial peak at $180 \mathrm{~min}$, with RE reaching a major peak at $420 \mathrm{~min}$ and triacylglycerol a second peak at $360 \mathrm{~min}$. ApoB-48 demonstrated an initial peak at $120 \mathrm{~min}$ and a later peak at $360 \mathrm{~min}$. The RE concentrations did not return to baseline levels at the end of the postprandial period (Fig. 1(c)).

\section{Discussion}

The aim of this study was to monitor the contribution of intestinally-derived lipoproteins to the lipaemic responses induced by three test meals of varying MUFA and SFA contents. The test meals were modified to provide 12,17 and $24 \%$ dietary energy as MUFA, with corresponding reductions in the SFA contents of the meals; PUFA contents of the three meals were identical. In this way the three test meals represented the range of MUFA and SFA intakes which are observed in human diets worldwide, with the $12 \%$ MUFA test meal reflecting the habitual fatty acid intake of the UK population, $17 \%$ MUFA that of a typical current Mediterranean diet and 24\% MUFA reflecting the intake of MUFA and SFA recorded in Crete at the time of the Seven Countries Study (Keys et al. 1970). The fat content of the test meals was maintained at $40 \mathrm{~g}$, which was chosen to reflect the average fat content of a typical main meal and enabled postprandial responses to be

Fig. 1. Postprandial triacylglycerol (TAG) $(-\bullet-, \mathrm{mmol} / \mathrm{l})$, retinyl ester (RE) $(-\bigcirc-, \mu \mathrm{g} / \mathrm{ml})$ and apolipoprotein (apo) B-48 ( $\leftarrow, \mu \mathrm{g} / \mathrm{ml})$ responses in the plasma TAG-rich lipoprotein fraction following consumption at time 0 of meals containing (a) 12, (b) 17 or (c) $24 \%$ dietary energy as monounsaturated fatty acids. Values, which are shown as changes from baseline (- - - ), are presented as mean values only with the standard error bars removed to improve clarity of the patterns of response for fifteen male volunteers. For details of meals and procedures, see Table 1 and pp. 52-53. 
determined following a moderate fat challenge typical of a standard meal.

The use of specific markers (apoB-48 and RE) for the intestinally-derived lipoproteins in the present study is an important addition since the simple measurement of triacylglycerol in a TRL fraction will include measurement of both CM- and VLDL-triacylglycerol. The labelling of $\mathrm{CM}$ using retinyl palmitate, in the form of an oil, was one of the methods used to monitor the metabolism of these particles during the $9 \mathrm{~h}$ test period. However, apoB-48, a structural protein of $\mathrm{CM}$ particles and their remnants, is now regarded as a more specific marker than the use of RE in the test meal (Krasinski et al. 1990a). The development of a specific competitive ELISA in our laboratory for the measurement of apoB-48 in the TRL fraction has enabled the accurate quantitation of the contribution of intestinally-derived lipoproteins during postprandial lipaemia (Lovegrove et al. 1996). The results show that there were no significant differences in postprandial lipaemic responses evaluated in terms of the AUC and incremental AUC or repeated measures ANOVA for triacylglycerol, RE and apoB-48 in the TRL fraction. These findings suggest that when meal MUFA and SFA contents are varied within the range of normal human dietary intakes, there are no differences in the rates of entry of $\mathrm{CM}$ or in the rates of clearance of $\mathrm{CM}$ and $\mathrm{CM}$ remnant particles from the circulation. These findings differ from those obtained by de Bruin et al. (1993) who showed more marked early RE and apoB-48 responses when subjects were given an oral olive oil emulsion than when they consumed either a sunflower oil or cream emulsion. Based on these findings, and those obtained from a comparison of the intravenous infusion of olive oil and sunflower oil emulsions (Brouwer et al. 1993), this group suggested that MUFA-enriched remnants are cleared more slowly and through a different route than PUFA-containing remnant particles. Differences between the present findings and those of de Bruin et al. (1993), who compared lipaemic responses to cream and olive oil, may be due to the presence of carbohydrate in the meals used in the present study which elicited a significant insulin response (results not shown), and to the fact that the cream used by de Bruin et al. (1993) might be expected to elicit a lower lipaemic response compared with both the oil emulsions. Cream contains significant amounts of medium-chain fatty acids which, because they are absorbed via the portal route, would not be expected to contribute to the CM response following a meal. The $12 \%$ MUFA meal used here contained moderate amounts of medium-chain fatty acids representative of levels found in the UK diet, but levels were not as high as those found in cream.

Overall the findings presented here suggest that substitution of meal SFA with MUFA offers no advantage in terms of attenuation of the total lipaemic response and no reduction in the circulating levels of intestinally-derived lipoproteins. This is unlike the situation we and others have observed with PUFA-containing test meals which, when compared with SFA-rich test meals, result in attenuated responses of plasma- and TRL-triacylglycerol (Zampelas et al. 1994). As recently reviewed, between-study comparisons of lipaemic responses to test meals of varying fatty acid composition are made difficult by the range and variations in test meal formulations used by different authors, although the consensus at the present time would appear to be that lipaemic responses vary in the order SFA $=$ MUFA $>n-6$ PUFA $>n-3$ PUFA (Williams, 1997, 1998).

Although there were no significant differences in the magnitudes of the postprandial triacylglycerol, apoB- 48 and $\mathrm{RE}$ responses, nor in the average times to reach their peak concentrations, there was a tendency for the patterns of response following the meals to differ as meal MUFA content increased (and SFA content decreased). Visual examination shows that on increasing the MUFA content of the test meal from 12 to 17 to $24 \%$, the patterns for each of the three variables shifted from a typical monophasic to a biphasic pattern, so that for the $24 \%$ MUFA meal, a second peak was observed for all three markers in the latter half of the postprandial period. Although these differences in pattern of response were not shown to be significantly different when analysed using repeated measures ANOVA, this was largely because of the large inter-individual differences which typify human postprandial responses and larger numbers of subjects may be required to achieve statistical significance. It is possible that the tendency towards a biphasic response seen in the present study following the $24 \%$ MUFA meal reflects differences in the gastrointestinal handling of the highMUFA meal, or possibly in the clearance of MUFA-rich $\mathrm{CM}$, or it may reflect differences in fatty acid-induced secretion of VLDL particles in the late postprandial period. We speculate that the two-phase response to the $24 \%$ MUFA meal reflects two separate phases of entry of $\mathrm{CM}$, reflecting effects of MUFA-rich meals on gastric emptying. In a previous study using identical test-meal formulations to those employed here, we did not observe a biphasic response to a $24 \%$ MUFA meal in Greek subjects habituated to a high-MUFA diet, and indeed, an earlier and sharper monophasic rise and decline in postprandial triacylglycerol was seen in southern compared with northern Europeans given either a $12 \%$ or $24 \%$ MUFA meal (Zampelas et al. 1998). It is possible that the biphasic response to the $24 \%$ MUFA meal seen in the UK subjects here reflects a specific gastrointestinal response to a highMUFA meal in subjects not habituated to high-MUFA diets. Further studies are required to elucidate mechanisms underlying differences in patterns of response to meals of varying fatty acid composition and effects of habitual diet on acute meal responses.

There has been much debate regarding the validity of the vitamin A loading technique for investigating $\mathrm{CM}$ metabolism and the results presented here do support the observation made by other authors that the peak retinyl palmitate/RE response is delayed relative to those of triacylglycerol and apoB-48 (Table 2). The time to reach peak RE concentration was found to be consistently later for RE than for triacylglycerol or apoB-48 irrespective of the composition of the fatty acids in the test meal. However, a delay in the retinyl palmitate/RE peak is not a consistent finding in the literature and others have shown that the delay varies depending on the form in which the vitamin $\mathrm{A}$ is given (aqueous, tablet or oil) and the predominant fatty acids in the test meals (Krasinski et al. 1990a). The 
predominant fatty acids commonly used in test meals to determine the validity of the vitamin A loading method are derived mainly from SFA (Weintraub et al. 1988; Groot et al. 1991; Rassin et al. 1992; Schrenzenmeir et al. 1992; Cohn et al. 1993) or PUFA (Krasinski et al. 1990a,b; Averna et al. 1993; de Bruin et al. 1993; Karpe et al. 1995) and one study has suggested that high-PUFA test meals may result in a greater delay in the absorption of vitamin A (Karpe et al. 1995). Despite criticism of the vitamin A loading method, its use in the present study has provided valuable additional information in verifying different patterns of response to meals of different fatty acid composition and confirming the dietary origin of plasma triacylglycerol peak responses. However, the fact that $\mathrm{RE}$ response is delayed relative to that of triacylglycerol and apoB-48 means that when used as the sole marker of $\mathrm{CM}$ and $\mathrm{CM}$ remnants it may give a misleading picture of the duration of CM-induced lipaemia, and of retention of remnants particles.

In conclusion, the contribution of intestinally-derived lipoproteins to the extent and duration of postprandial lipaemia following test meals of different MUFA and SFA composition was evaluated using measurements of TRLtriacylglycerol, apoB-48 and RE. No significant differences were found in the total lipaemic response measured as the AUC and incremental AUC or repeated measures ANOVA for each of the markers used. However, as meal MUFA content increased there was a tendency for the monophasic response typically seen after a single meal following an overnight fast to be replaced by a biphasic response with both early and late peaks for triacylglycerol, apoB-48 and RE. Further work is required to identify the precise locus for this effect, which may be specific to subjects not habituated to high-MUFA diets.

\section{Acknowledgements}

We wish to thank the European Union for grant support and in particular for their support of Dr K. G. Jackson, Dr A. Zampelas and Mrs C. C. Culverwell.

\section{References}

Averna M, Scip RL, Mankowitz K \& Schonfeld G (1993) Postprandial lipaemia in subjects with hypobetalipoproteinaemia and a single intestinal allelle for apo B-48. Journal of Lipid Research 34, 1957-1967.

Berr F \& Kern F Jr (1984) Plasma clearance of chylomicrons labeled with retinyl palmitate in healthy human subjects. Journal of Lipid Research 25, 805-812.

Brouwer CB, de Bruin TWA, Jansen H \& Erkelens DW (1993) Different clearance of intravenously administered olive oil and soybean oil emulsions: role of hepatic lipase. American Journal of Clinical Nutrition 57, 533-539.

Brown MS \& Goldstein JL (1983) Lipoprotein metabolism in the macrophage: implications for cholesterol deposition in atherosclerosis. Annual Reviews of Biochemistry 52, 223261.

Cohn JS, Johnson EJ, Miller JS, Cohn SD, Milne RW, Marcel YL, Russell RM \& Schaefer EJ (1993) Contribution of apo B-48 and apo B-100 triglyceride-rich lipoproteins (TRL) to postprandial increases in the plasma concentration of TRL triglycerides and retinyl esters. Journal of Lipid Research 34, 2033-2040.

Cortner JA, Coates PM, Le N-A, Cryer DR, Ragni MC, Faulkner A \& Langer T (1987) Kinetics of chylomicron remnant clearance in normal and hyper-lipoproteinemic subjects. Journal of Lipid Research 28, 195-206.

de Bruin TWA, Brouwer CB, van Linde-Sibenius Trip M, Jansen H \& Erkelens DW (1993) Different postprandial metabolism of olive oil and soybean oil: a possible mechanism of the high density lipoprotein conserving effect of olive oil. American Journal of Clinical Nutrition 58, 447-483.

Demacker PNM, Reijnen IGM, Katan MB, Stuyt PMJ \& Stahlenhoef AFH (1991) Increased removal of remnants of triglyceride-rich lipoproteins on a diet rich in polyunsaturated fatty acids. European Journal of Clinical Investigation 21, 197-203.

Edelstein C \& Scanu M (1986) Precautionary measures for collecting blood destined for lipoprotein isolation. Methods in Enzymology 128, 151-155.

Groot PHE, van Stiphout WAHJ, Krauss XH, Jansen H, van Tol A, van Ramshorst E, Chin-On S, Hofman A, Cresswell SR \& Hanekas L (1991) Postprandial lipoprotein metabolism of normolipidaemic men with and without coronary artery disease. Arteriosclerosis and Thrombosis 11, 653-662.

Grundy SM \& Mok HYI (1976) Chylomicron clearance in normal and hyperlipidaemic man. Metabolism, Clinical and Experimental 25, 1225-1291.

Hazzard WR \& Bierman EL (1976) Delayed clearance of chylomicron remnants following vitamin-A-containing oral fat loads in broad- $\beta$ disease (Type III Hyperlipoproteinaemia). Metabolism, Clinical and Experimental 25, 777-801.

Karpe F, Bell M, Bjorkegren J \& Hamsten A (1995) Quantification of postprandial triglyceride-rich lipoproteins in healthy men by retinyl ester labelling and simultaneous measurement of apolipoprotein B-48 and B-100. Arteriosclerosis, Thrombosis and Vascular Biology 15, 199-207.

Karpe F \& Hamsten A (1995) Postprandial lipoprotein metabolism and atherosclerosis. Current Opinions in Lipidology 6, 123-129.

Keys A (1970) Coronary artery disease in seven countries. Circulation 41, I1-I211.

Kita T, Goldstein JL, Brown MS, Watanabe Y, Hornick CA \& Havel RJ (1982) Hepatic uptake of chylomicron remnants in WHHL rabbits: a mechanism genetically distinct from the low density lipoprotein receptor. Proceedings of the National Academy of Sciences USA 79, 3623-3627.

Krasinski SD, Cohn JS, Russell M \& Schaefer EJ (1990a) Postprandial plasma vitamin A metabolism in humans: a reassessment of the use of plasma retinyl esters as markers for intestinally derived chylomicrons and their remnants. Metabolism 39, 357-365.

Krasinski SD, Cohn JS, Schaefer EJ \& Russell RM (1990b) Postprandial retinyl ester response is greater in older subjects compared with younger subjects. Journal of Clinical Investigation 85, 883-892.

Levy E, Roy CC, Goldstein R, Bar-On H \& Ziv E (1991) Metabolic fate of chylomicrons obtained from rats maintained on diets varying in fatty acid composition. Journal of the American College of Nutrition 10, 69-78.

Lovegrove J, Isherwood SG, Jackson KG, Williams CM \& Gould BJ (1996) Quantification of apolipoprotein B-48 in triacylglycerol-rich lipoproteins by a specific enzyme-linked immunosorbent assay. Biochimica et Biophysica Acta 1301, 221-229.

Mahley RW (1982) Atherogenic hyperlipoproteinemia. The cellular and molecular biology of plasma lipoproteins altered by dietary fat and cholesterol. Medical Clinics of North America: Lipid Disorders 66, 375-402.

Matthews JNS, Altman DG, Campbell MJ \& Royston P (1990) 
Analysis of serial measurements in medical research. British Medical Journal 300, 230-235.

Rassin T, Liron M, Rubenstein A, Arad J \& Weintraub MS (1992) Vitamin A loading: an indicator of postprandial lipoprotein clearance in healthy and hypertriglyceridemic subjects. Israeli Journal of Medical Science 28, 706-710.

Ross AC \& Zilversmit DB (1977) Chylomicron remnant cholesteryl esters as the major constituent of very low density lipoproteins in plasma of cholesterol-fed rabbits. Journal of Lipid Research 18, 169-181.

Ruotolo G, Zhang H, Bentsianov V \& Le N-A (1992) Protocol for the study of the metabolism of retinyl esters in plasma lipoproteins during postprandial lipaemia. Journal of Lipid Research 33, 1541-1549.

Sakr SW, Haourigui M, Paul JL, Soni T, Vachter D \& Girard-Globa A (1997) Fatty acid composition of an oral fat load affects chylomicron size in human subjects. British Journal of Nutrition 77, 19-31.

Schrezenmeir J, Weber P, Probst R, Biesalski HK, Luley C, Prellwitz W, Krause U \& Beyer J (1992) Postprandial pattern of triglyceride-rich lipoprotein in normal-weight humans after an oral fat load: exaggerated triglycerides and altered insulin response in some subjects. Annals of Nutrition and Metabolism 36, 186-196.

Stender S \& Zilversmit DB (1982) Comparison of cholesteryl ester transfer from chylomicrons and other plasma lipoproteins to aorta intima-media of cholesterol-fed rabbit. Arteriosclerosis $\mathbf{2}$, 493-499.

Weintraub MS, Eisenberg S \& Breslow JL (1987) Different patterns of postprandial lipoprotein metabolism in normal, Type IIa, Type III and Type IV hyperlipoproteinemic individuals. Journal of Clinical Investigation 79, 1110-1119.

Weintraub MS, Zechner R, Brown A, Eisenberg S \& Breslow JL (1988) Dietary polyunsaturated fats of the $\omega-6$ and $\omega-3$ series reduce postprandial lipoprotein levels: chronic and acute effects of fat saturation on postprandial lipoprotein metabolism. Journal of Clinical Investigation 82, 1884-1893.

Williams CM (1997) Postprandial lipid metabolism: effects of dietary fatty acids. Proceedings of the Nutrition Society 56, 679-692.

Williams CM (1998) Dietary interventions affecting chylomicron and chylomicron remnants. Atherosclerosis (In the Press).

Zampelas A, Peel A, Gould BJ, Wright J \& Williams CM (1994) Polyunsaturated fatty acids of the $n-6$ and $n-3$ series: effects on postprandial lipid and apolipoprotein levels in healthy men. European Journal of Clinical Nutrition 48, 88-96.

Zampelas A, Roche H, Knapper JME, Jackson KG, Tornaritis M, Hatzis C, Gibney MJ, Kafatos A, Gould BJ, Wright J \& Williams CM (1998) Differences in postprandial lipaemic responses between northern and southern Europeans. Atherosclerosis 139, 83-93. 


\section{Public Health Nutrition}

Essential reading for everyone involved with nutritional epidemiology research, the role of nutrition in disease prevention, and identifying practical solutions to public health problems.

1999, Volume 2, 4 issues

ISSN: 1368-9800

\section{Journal Editors}

Dr Barrie Margetts (Editor-in-Chief)

Southampton General Hospital, UK

Dr Lenore Kohlmeier (Editor, North America)

Schools of Public Health and Medicine, University of North Carolina at Chapel Hill, USA

Dr Frans Kok

Wageningen Agricultural University, The Netherlands

Dr Michael Nelson

University of London, UK

To order your subscription, reserve a FREE sample copy, or for more information, contact:

(10) CABI Publishing

CABI Publishing, CAB International,

Wallingford, Oxon, OX10 8DE, UK

Tel: +44 (0)1491 832111 Fax: +44 (0)1491 829292

Email: publishing@cabi.org

CABI Publishing, CAB International,

10 East 40th Street, Suite 3203,

New York, NY 10016, USA

Tel: 2124817018 Toll free: 8005284841

Fax: 2126867993 Email: cabi-nao@cabi.org

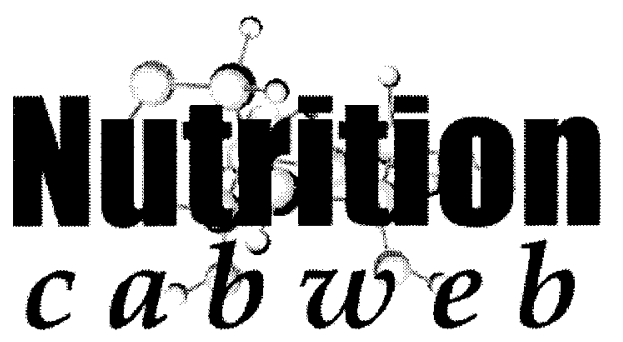

http://nutrition.cabweb.org

Available on the Internet in 1999!

Visit Nutrition CABWeb for more details and for tables of contents

Institutional subscription rate:

$\$ 310.00$ North and South America $£ 175.00$ Rest of World

A special subscription rate is azailable for members of The Nutrition Society

$\$ 80.00$ North and South America 